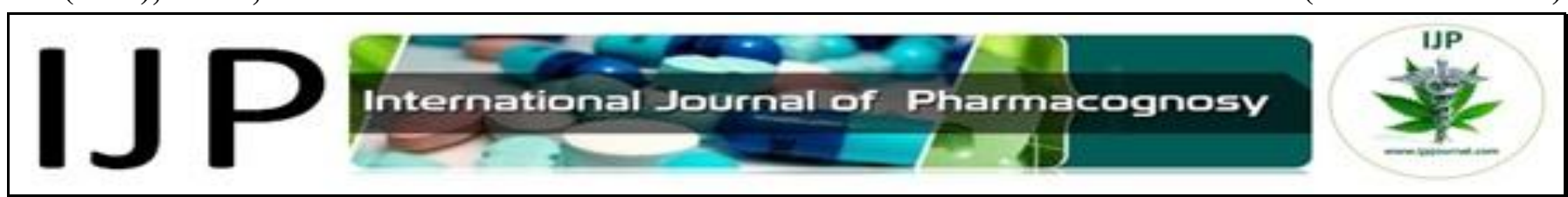

Received on 09 June 2015; received in revised form, 29 June 2015; accepted, 28 July 2015; published 31 July 2015

\title{
DETERMINATION OF MEXILETINE IN PHARMACEUTICAL PREPARATIONS BY LINEAR SWEEP VOLTAMMETRY
}

\section{Bilal Yilmaz * and Gulsah Nazik}

Department of Analytical Chemistry, Faculty of Pharmacy, Ataturk University, 25240, Erzurum, Turkey.

Keywords:

Mexiletine, Cyclic voltammetry, Linear sweep voltammetry, Validation

Correspondence to Author:

Bilal Yilmaz

Department of Analytical

Chemistry, Faculty of Pharmacy,

Ataturk University, 25240, Erzurum,

Turkey.

E-mail: yilmazb@atauni.edu.tr
ABSTRACT: A simple and rapid method for the determination of mexiletine in pharmaceutical preparations was developed and validated using linear sweep voltammetry (LSV). The proposed method was based on electrochemical oxidation of mexiletine at a platinum electrode in an acetonitrile solution containing $0.1 \mathrm{M} \mathrm{LiCIO}_{4}$. The well-defined an oxidation peak was observed at $+1.11 \mathrm{~V}$. The calibration curve was linear for mexiletine at the concentration range of $5-70 \mu \mathrm{g} / \mathrm{mL}$ for LSV method. Intraand inter-day precision values for mexiletine were less than 2.73 , and accuracy (relative error) was better than $3.89 \%$. The mean recovery of mexiletine was $100.1 \%$ for a pharmaceutical preparation. No interference was found excipient at the selected assay conditions. The method was found to be specific, precise and accurate. The method was applied for the quality control of commercial mexiletine capsule form to quantify the drug and to check the formulation content uniformity.
INTRODUCTION: Arrhythmias, commonly observed as atrial fibrillation, atrial flutter, atrial tachycardia, ventricular tachycardia, and premature beats, are the consequences of abnormal autorhythmicity or conduction disturbance of heart. Generally, antiarrhythmic drugs therapy is preferred for patients with cardiac arrhythmia 1,2,3. Mexiletine Fig. 1, is an antiarrhythmic agent used in the treatment of ventricular arrhythmia ${ }^{4}$. It is available in the form of the hydrochloride salt, a single dose ranges from $50-400 \mathrm{mg}$, and a daily dose up to $1500 \mathrm{mg}$ can be prescribed. The bioavailability of mexiletine is $80-90 \%$ by the oral route. Peak plasma concentration occurs in 1-4 h after ingestion 5 .

\begin{tabular}{|c|c|}
\hline QUICK RESPONSE CODE & DOI: \\
\hline \multicolumn{2}{|c|}{ DOI link: http://dx.doi.org/10.13040/IJPSR.0975-8232.IJP.2(7).335-41 } \\
\hline
\end{tabular}

Several methods have been reported for determination of mexiletine including HighPerformance Liquid Chromatography (HPLC) ${ }^{6-14}$, LC-MS/MS ${ }^{15}$ and Gas Chromatography-Mass Spectrophotometry (GC-MS) ${ }^{16-18}$ in plasma and other biological fluids. The USP XXII ${ }^{19}$ describes a reverse phase HPLC method for its assay while the BP $93^{20}$ describes a nonaqueous titration method.

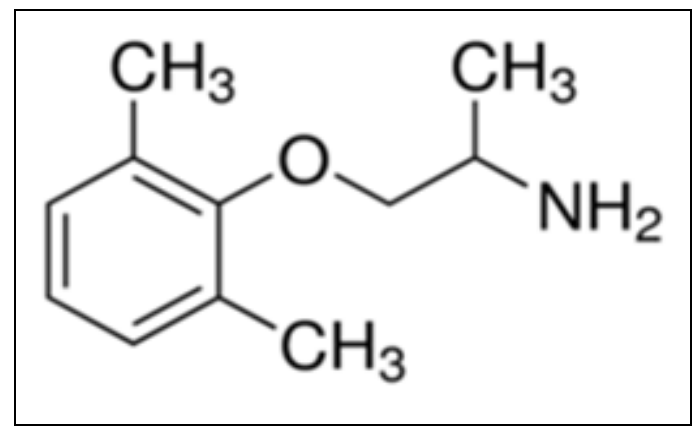

FIG. 1: CHEMICAL STRUCTURE OF MEXILETINE

The reported methods were influenced by the interference of endogenous substances and potential loss of drugs in the re-extraction 
procedure and involving lengthy, tedious and timeconsuming plasma sample preparation and extraction processes and requiring sophisticated and expensive instrumentation. The development of a new method capable of determining drug amount in pharmaceutical dosage forms is important. Electroanalytical techniques have been used for the determination of a wide range of drug compounds with the advantages that there are, in most, instances no need for derivatization and that these techniques are less sensitive to matrix effects than other analytical techniques. Additionally, the application of electrochemistry includes the determination of electrode mechanism. Redox properties of drugs can give insights into their metabolic fate or their in-vivo redox processes or pharmacological activity ${ }^{21-24}$.

Despite the analytical importance of the electrochemical behavior and oxidation mechanism of mexiletine, no report has been published on the voltammetric study of the electrochemical oxidation of mexiletine in non-aqueous media. It is well known that the experimental and instrumental parameters directly affect the electrochemical process and voltammetric response of drugs. Consequently, it would be interesting to investigate the oxidation process of mexiletine in aprotic media.

Therefore, the goal of this work was the development of a new LSV method for the direct determination of mexiletine in pharmaceutical preparation without any time-consuming extraction or evaporation steps before drug assay. This paper describes fully validated simple, rapid, selective and sensitive procedures for the determination of mexiletine employing LSV methods the platinum disc electrode. Besides, the method was successfully applied for the quality control of commercial mexiletine quantify the drug and to check the formulation content uniformity.

\section{MATERIALS AND METHODS:}

Chemicals and Reagents: Mexiletine $\mathrm{HCl}$ (99.6\% purity) was obtained by Eczacıbaşı Pharmaceutical Industry (Istanbul, Turkey). Acetonitrile (Fluka for HPLC analysis) was purified by drying with calcium hydride, followed by distillation from phosphorus pentoxide. After purification in order to eliminate its water content as much as possible, it was kept over molecular sieves. Lithium perchlorate $\left(\mathrm{LiClO}_{4}\right)$ were purchased from Fluka and used as received without further purification. Mexitil capsule containing $200 \mathrm{mg}$ mexiletine was obtained by the pharmacy (Erzurum, Turkey).

Electro - chemical Instrumentation: Electrochemical experiments were performed on a Gamry Potentiostat Interface 1000 controlled with software PHE 200 and PV 220. All measurements were carried out in a single-compartment electrochemical cell with a standard three-electrode arrangement. A platinum disk with an area of 0.72 $\mathrm{cm}^{2}$ and a platinum wire were used as the working and the counter electrodes, respectively. The working electrode was successively polished with 1.0, 0.3 and $0.05 \mu \mathrm{m}$ alumina slurries (Buehler) on micro cloth pads (Buehler).

After each polishing, the electrode was washed with water and sonicated for $10 \mathrm{~min}$ in acetonitrile. Then, it was immersed in a hot piranha solution (3:1, $\mathrm{H}_{2} \mathrm{SO}_{4}, 30 \% \mathrm{H}_{2} \mathrm{O}_{2}$ ) for $10 \mathrm{~min}$, and rinsed copiously with water. All potentials were reported versus $\mathrm{Ag} / \mathrm{AgCl} / \mathrm{KCl}(3.0 \mathrm{M})$ reference electrode (BAS Model MF-2078) at room temperature. The electrolyte solutions were degassed with purified nitrogen for $10 \mathrm{~min}$ before each experiment and bubbled with nitrogen during the experiment.

Preparation of the Standard and Quality Control Solutions: The stock standard solution of mexiletine was prepared in $0.1 \mathrm{M} \mathrm{LiClO}_{4} /$ acetonitrile to a concentration of $100 \mu \mathrm{g} / \mathrm{mL}$. Working standard solutions were prepared from the stock solution. Standard solutions were prepared as $5-70 \mu \mathrm{g} / \mathrm{mL}$ for LSV. The quality control (QC) solutions were prepared by adding aliquots of a standard working solution of mexiletine to final concentrations of 15,25 and $55 \mu \mathrm{g} / \mathrm{mL}$ for LSV.

\section{Procedure for Pharmaceutical Preparations:} Accurately weighed the amount of powder for injection equivalent to $10 \mathrm{mg}$ of mexiletine was transferred into $100 \mathrm{ml}$ calibrated flask and $50 \mathrm{ml}$ of $0.1 \mathrm{M} \mathrm{LiClO}_{4} /$ acetonitrile was added, and then the flask was sonicated to $10 \mathrm{~min}$ at room temperature. The flask was filled to volume with $0.1 \mathrm{M} \mathrm{LiClO}_{4} /$ acetonitrile. The resulting solutions in both the cases were filtered through Whatman filter paper no 42 and suitably diluted to get final 
concentration within the limits of linearity for the respective proposed method. The drug content of mexiletine was calculated from the current potential curve.

\section{RESULTS AND DISCUSSION:}

Voltammetric Behavior of Mexiletine: The electrochemical reaction of mexiletine was investigated at the $\mathrm{Pt}$ disc electrode in an acetonitrile solution containing $0.1 \mathrm{M} \mathrm{LiClO}_{4}$ as the supporting electrolyte by using cyclic voltammetry (CV). Fig. 2 shows a typical cyclic voltammogram of $30 \mu \mathrm{g} / \mathrm{mL}$ mexiletine recorded under these conditions for the scan rate of $0.1 \mathrm{~V} / \mathrm{s}$. In the anodic sweep, an oxidation peak is seen at about potential of $+1.11 \mathrm{~V}$.

To gain a deeper insight into the voltammetric waves, the effect of scan rate on the anodic peak currents $\left(I_{\mathrm{m}}\right)$ and peak potentials $\left(\mathrm{E}_{\mathrm{p}}\right)$ was studied in the range of $0.01-1 \mathrm{~V} / \mathrm{s}$ of the potential scan rates in an acetonitrile solution containing $30 \mu \mathrm{g} / \mathrm{mL}$ concentration of mexiletine.

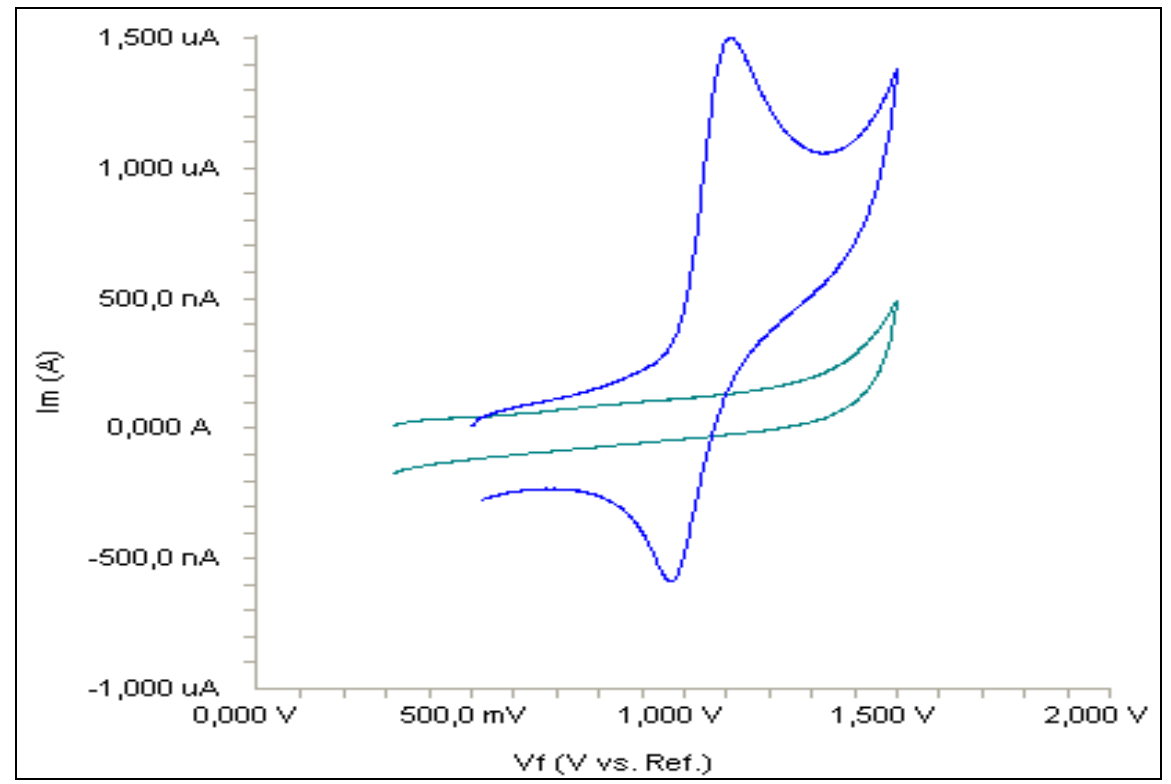

FIG. 2: CYCLIC VOLTAMMOGRAM FOR THE OXIDATION OF $30 \mu \mathrm{g} / \mathrm{mL}$ MEXILETINE IN ACETONITRILE CONTAINING 0.1 M $\mathrm{LiClO}_{4}$ AT Pt DISK ELECTRODE, SCAN RATE: 0.1 V/s

The representative linear sweep voltammograms obtained at the Pt electrode for $30 \mu \mathrm{g} / \mathrm{mL}$ mexiletine as a function of the scan rate. However, the plots of logarithm of peak currents versus the logarithm of scan rates for $30 \mu \mathrm{g} / \mathrm{mL}$ concentration of mexiletine display straight lines with 0.48 slope, which are close to the theoretical value of 0.5 expected for an ideal diffusion-controlled electrode process ${ }^{25} . \log$ Im-log $v$ curve is more eligible for this aim; therefore, a diffusional process for peak should be considered. These results suggest that the redox species are diffusing freely from solution and not precipitating onto the electrode surface. The reason for this behavior may be due to the solubility of the intermediate species in acetonitrile or poor adherence of products on the electrode surface.The oxidation peak potential (Epa) for peaks shift toward more positive values with increasing scan rate. The relationship between the peak potential and scan rate is described by the following equation ${ }^{26}$,

$$
E_{p a}=E^{0^{\prime}}+R T /\left[(1-\alpha) n_{a} F\right]\left[0.78+\ln \left(D^{1 / 2} k_{x}^{-1}\right)-0.5 \ln R T /\left[(1-\alpha) n_{a} F\right]\right]+R T /\left[(1-\alpha) n_{a} F\right] / 2 \ln v
$$

And from the variation of peak potential with scan rate $\alpha \mathrm{n}_{\mathrm{a}}$ can be determined, where $\alpha$ is the transfer coefficient and $n_{a}$ is the number of electrons transferred in the rate determining step. The slope indicates the value of $\alpha \mathrm{n}_{\mathrm{a}}$ is 1.0 for the peak. Also, this value obtained indicate the total irreversibility of the electron transfer processes. This result shows that the chemical step is a following fast reaction coupled to a charge transfer. 
Validation of the Method: The validation was carried out by establishing specificity, linearity, accuracy, precision, limit of detection (LOD), limit of quantification (LOQ), stability, recovery according to ICH Q2B recommendations ${ }^{27,28 .}$

Specificity: The effects of common excipients and additives were tested for their possible interferences in the assay of mexiletine. The simulated and placebo samples were prepared and analyzed. It has not been determined any interference of these substances at the levels found in dosage forms. Excipient that was used in this preparation was the most commonly used by the pharmaceutical industry. The specificity of the method was investigated by observing any interference encountered from the common tablet excipients such as titanium dioxide, sodium chloride, talc, lactose, starch, and magnesium stearate. These excipients did not interfere with the proposed method.

Linearity: Standard solutions were prepared as 5$70 \mu \mathrm{g} / \mathrm{mL}(5,10,20,30,40,50$ and 70$)$ for LSV Fig. 3.

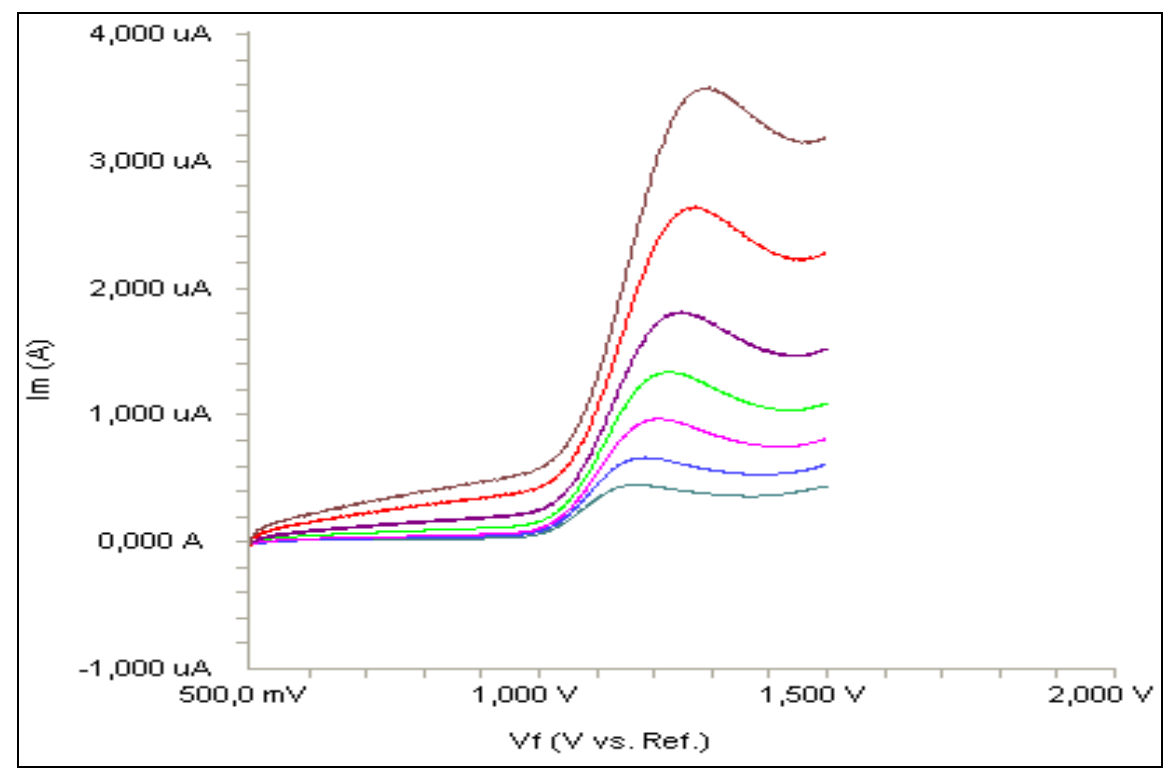

FIG. 3: LINEAR SWEEP VOLTAMMOGRAMS FOR DIFFERENT CONCENTRATIONS OF MEXILETINE IN ACETONITRILE SOLUTION CONTAINING 0.1 M LiCIO 4 (5, 10, 20, 30, 40, 50 AND $70 \mu \mathrm{g} / \mathrm{ml})$

TABLE 1: LINEARITY OF MEXILETINE

\begin{tabular}{cccccccc}
\hline Method & Range $(\boldsymbol{\mu g} / \mathbf{m L})$ & $\mathbf{L R}^{\mathbf{a}}$ & $\mathbf{S}_{\mathbf{a}}$ & $\mathbf{S}_{\mathbf{b}}$ & $\mathbf{R}^{2}$ & LOD & $\mathbf{L O Q}$ \\
\hline LSV & $5-70$ & $\mathrm{y}=51.076 \mathrm{x}+68.141$ & 4.610 & 0.022 & 0.9917 & 1.00 & 3.00 \\
\hline
\end{tabular}

Based on three calibration curves, LR: Linear regression, $S_{\mathrm{a}}$ : Standard deviation of intercept of the regression line, $S_{\mathrm{b}}$ : Standard deviation of the slope of the regression line, $\mathrm{R}^{2}$ : Determination of correlation, $\mathrm{y}$ : Peak current, $\mathrm{x}$ : Mexiletine concentration $(\mu \mathrm{g} / \mathrm{mL})$, LOD: Limit of detection, LOQ: Limit of quantification

A calibration curve was constructed for mexiletine standard by plotting the concentration of compound versus peak current responses. Its correlation coefficients evaluated the calibration curves. The correlation coefficients (r) of all the calibration curves were consistently greater than 0.99 . The linear regression equations were calculated by the least squares method using Microsoft Excel $^{\circledR}$ program and summarized in Table $\mathbf{1}$.

Accuracy and Precision: The accuracy of the assay methods was determined for both intra-day and inter-day variations using the quality control
(QC) samples. The precision of the assay was determined by repeatability (intra-day) and intermediate precision (inter-day). Repeatability refers to the use of the analytical procedure within a laboratory over a short period that was evaluated by assaying the QC samples during the same day. Intermediate precision was assessed by comparing the assays on different days ( 2 days). The intra-day accuracy ranged from $3.51 \%$ to $0.64 \%$ and precision from $2.73 \%$ to $2.04 \%$ Table 2 . The results obtained from intermediate precision (interday) also indicated a good method of precision. 
TABLE 2: PRECISION AND ACCURACY OF MEXILETINE

\begin{tabular}{|c|c|c|c|c|c|c|c|}
\hline \multirow[t]{2}{*}{ Method } & \multirow{2}{*}{$\begin{array}{c}\text { Added } \\
(\mu \mathrm{g} / \mathrm{mL})\end{array}$} & \multicolumn{3}{|c|}{ Intra-day } & \multicolumn{3}{|c|}{ Inter-day } \\
\hline & & $\begin{array}{c}\text { Found } \pm \text { SD }^{\mathbf{a}} \\
(\mu \mathrm{g} / \mathrm{mL})\end{array}$ & Accuracy & $\begin{array}{l}\text { Precision } \\
\text { RSD \% }\end{array}$ & $\begin{array}{c}\text { Found } \pm \text { SD } \\
(\mu \mathrm{g} / \mathrm{mL})\end{array}$ & Accuracy $^{c}$ & $\begin{array}{c}\text { Precision } \\
\text { RSD \% }^{\text {b }} \\
\end{array}$ \\
\hline \multirow[t]{3}{*}{ LSV } & 15 & $15.33 \pm 0.419$ & 2.20 & 2.73 & $15.20 \pm 0.372$ & 1.33 & 2.45 \\
\hline & 25 & $25.16 \pm 0.597$ & 0.64 & 2.37 & $24.89 \pm 0.418$ & -0.44 & 1.68 \\
\hline & 55 & $53.07 \pm 1.082$ & -3.51 & 2.04 & $52.86 \pm 0.972$ & -3.89 & 1.84 \\
\hline
\end{tabular}

a SD: Standard deviation of six replicate determinations, b RSD: Relative standard deviation, c Accuracy: (\%relative error) (found-added)/added $\times 100$

Limits of Detection (LOD) and Quantification (LOQ): The LOD and LOQ of mexiletine by the proposed method was determined using calibration standards. LOD and LOQ values were calculated as $3.3 \sigma / S$, and $10 \sigma / S$, respectively, where $S$ is the slope of the calibration curve and $\sigma$ is the standard deviation of $y$-intercept of regression equation $(n=6)^{28}$. The LOD and LOQ values of the methods were summarized in Table 1.

Stability: To evaluate the stability of mexiletine, standard solutions were prepared separately at concentrations covering the low, medium and higher ranges of a calibration curve for different temperature and times. These solutions were stored at room temperature, refrigeratory $\left(4^{\circ} \mathrm{C}\right)$ and frozen $\left(-20^{\circ} \mathrm{C}\right)$ temperature for $24 \mathrm{~h}$ and $72 \mathrm{~h}$. Stability measurements were carried out with LSV method.
The results were evaluated comparing these measurements with those of standards and expressed as percentage deviation, and mexiletine was found as stable at room temperature, 4 and -20 ${ }^{\circ} \mathrm{C}$ for at least $72 \mathrm{~h}$ Table 3.

Recovery: To determine the accuracy of the LSV method and to study the interference of formulation additives, the recovery was checked as three different concentration levels. Analytical recovery experiments were performed by adding known amount of pure drugs to pre-analyzed samples of commercial drug form. The recovery values were calculated by comparing concentration obtained from the spiked samples with actually added concentrations. These values are also listed in Table 4.

TABLE 3: STABILITY OF MEXILETINE IN SOLUTION

\begin{tabular}{|c|c|c|c|c|c|c|c|}
\hline \multicolumn{2}{|c|}{$\begin{array}{l}\text { Stability } \\
(\%)\end{array}$} & \multicolumn{2}{|c|}{$\begin{array}{l}\text { Room temperature stability, } \\
\text { (Recovery \% } \pm \text { RSD) }\end{array}$} & \multicolumn{2}{|c|}{$\begin{array}{l}\text { Refrigeratory stability, }+4^{\circ} \mathrm{C} \\
\text { (Recovery } \% \pm \text { RSD) }\end{array}$} & \multicolumn{2}{|c|}{$\begin{array}{c}\text { Frozen stability, }-20^{\circ} \mathrm{C} \\
\text { (Recovery \% } \pm \text { RSD) }\end{array}$} \\
\hline Method & Added $(\mu \mathrm{g} / \mathrm{mL})$ & $24 \mathrm{~h}$ & $72 \mathrm{~h}$ & $24 \mathrm{~h}$ & $72 \mathrm{~h}$ & $24 \mathrm{~h}$ & $72 \mathrm{~h}$ \\
\hline LSV & 15 & $98.6 \pm 1.52$ & $100.8 \pm 3.64$ & $98.6 \pm 2.65$ & $97.4 \pm 2.32$ & $96.7 \pm 2.16$ & $98.4 \pm 2.46$ \\
\hline & 30 & $96.4 \pm 2.21$ & $99.4 \pm 2.92$ & $101.2 \pm 3.09$ & $99.8 \pm 1.06$ & $98.8 \pm 1.92$ & $99.1 \pm 2.41$ \\
\hline & 60 & $97.7 \pm 3.16$ & $99.7 \pm 1.68$ & $99.3 \pm 2.18$ & $98.3 \pm 2.28$ & $102.1 \pm 1.86$ & $98.2 \pm 0.74$ \\
\hline
\end{tabular}

RSD: Relative standard deviation of six replicate determinations

TABLE 4: RECOVERY VALUES OF MEXILETINE IN PHARMACEUTICAL PREPARATION

\begin{tabular}{cccccc}
\hline Method & $\begin{array}{c}\text { Mexitil } \\
\text { Capsule }\end{array}$ & $\begin{array}{c}\text { Added } \\
(\boldsymbol{\mu g} / \mathbf{m L})\end{array}$ & $\begin{array}{c}\text { Found } \pm \text { SD } \\
(\boldsymbol{\mu g} / \mathbf{m L})\end{array}$ & $\begin{array}{c}\text { Recovery } \\
(\boldsymbol{\%})\end{array}$ & $\begin{array}{c}\mathbf{R S D}^{\mathbf{a}} \\
(\boldsymbol{\%})\end{array}$ \\
\hline LSV & $(200 \mathrm{mg})$ & 5 & $4.97 \pm 0.201$ & 99.4 & 4.04 \\
& & 15 & $15.10 \pm 0.517$ & 100.7 & 3.42 \\
& & 35 & $33.85 \pm 0.941$ & 96.7 & 2.78 \\
\hline
\end{tabular}

SD: Standard deviation of six replicate determinations, RSD: Relative standard deviation, a Average of six replicate determinations.

The proposed method is very effective for the assay of mexiletine in capsules. The validity of the proposed method was presented by recovery studies using the standard addition method. For this purpose, a known amount of reference drug was spiked to formulated capsules, and the proposed methods estimated the nominal value of drug. Each level was repeated six times. The results were reproducible with low SD and RSD. No interference from the common excipients was observed. The proposed method was applied to commercially available capsules. The results were compared with those obtained by USP XXIII ${ }^{19}$ and BP $1993^{20}$ official methods. Statistical comparisons in terms of F-test for these methods were given in Table 5. There are no significant differences between the proposed methods and the official methods concerning the mean values and standard deviations at a $95 \%$ confidence level. 
TABLE 5: COMPARISON OF THE PROPOSED AND OFFICIAL METHODS

\begin{tabular}{|c|c|c|c|c|c|}
\hline $\begin{array}{l}\text { Commercial } \\
\text { preparation }\end{array}$ & Method & $\begin{array}{c}\% \text { Recovery } \\
\pm \text { SD }\end{array}$ & $\begin{array}{c}\text { Confidence } \\
\text { limits }\end{array}$ & $\begin{array}{c}\mathbf{P} \\
\text { value }\end{array}$ & F-test \\
\hline $\begin{array}{l}\text { Mexitil } \\
\text { capsule }\end{array}$ & $\begin{array}{c}\text { Official method } \\
\text { (BP 93) (Titration method) } 19\end{array}$ & $100.09 \pm 0.760$ & $200.19 \pm 0.690$ & 0.342 & $\begin{array}{l}\mathrm{F}_{\mathrm{c}}=1.38 \\
\mathrm{~F}_{\mathrm{t}}=3.00\end{array}$ \\
\hline
\end{tabular}

CONCLUSION: In the present study, the electrochemical behavior of mexiletine has been studied in nonaqueous media by $\mathrm{CV}$ method. Besides, a simple, rapid, sensitive, reliable, specific, accurate and precise LSV method for the determination of mexiletine in pharmaceutical preparation was developed and validated. The method described has been effectively and efficiently used to analyze mexiletine pharmaceutical preparations without any interference from the pharmaceutical excipients. The voltammetric run time of $1 \mathrm{~min}$ allows the analysis of a large number of samples in a short period. Therefore, the method can be used effectively without separation for routine analysis of mexiletine in pure form and its formulations.

\section{ACKNOWLEDGEMENT: Nil}

\section{CONFLICT OF INTEREST: Nil}

\section{REFERENCES:}

1. Hancox JC, Patel KC and Jones JV: Antiarrhythmics-from cell to the clinic: past, present and future. Heart 2000; 84 : 14-24.

2. Kannankeril PJ and Fish FA: Management of common arrhythmias and conduction abnormalities. Progr. Pediatric Cardiol 2003; 17: 41-52.

3. Zhu XY: The AADs in Pharmacology, Edition $3^{\text {rd }}$, 1993: 207.

4. Vaughan Williams EM: A classification of antiarrhythmic actions reassessed after a decade of new drugs. J Clin Pharmacol 1984; 24: 129-147.

5. Hasselbarth V, Doevendons JE and Wolf M: Kinetics and bioavailability of mexiletine in healthy subjects. Clin Pharmacol Ther 1981; 29: 729-736.

6. Kwok DKW, Igwemezie LCR, Kerr K and McErlane M: High-Performance Liquid Chromatographic analysis using a highly sensitive fluorogenic reagent, 2-anthroyl chloride, and stereoselective determination of the enantiomers of mexiletine in human serum. J. Chromatogr B 1994; 661: 271-280.

7. Fieger $\mathrm{H}$ and Wainer IW: Direct analysis of the enantiomers of mexiletine and its metabolites in plasma and urine using an HPLC-CSP. J Pharm Biomed Anal 1993; 11: 1173-1179.

8. Shibata N, Akabane $\mathrm{M}$, Minouchi $\mathrm{T}$, Ono $\mathrm{T}$ and Shimakawa H: Fluorimetric determination of mexiletine in serum by High-Performance Liquid Chromatography using pre-column derivatization with fluorescamine. J Chromatogr 1991; 566: 187-194.
9. Farid NA and White SM: Determination of mexiletine and its metabolites in serum by liquid chromatography with fluorescence detection. J Chromatogr 1983; 275: 458-462.

10. Freitag DG, Foster RT, Coutts RT and Pasutto FM: HighPerformance Liquid Chromatographic method for resolving the enantiomers of mexiletine and two major metabolites isolated from microbial fermentation media. $\mathbf{J}$ Chromatogr 1993; 616: 253-259.

11. Breithaupt $\mathrm{H}$ and Wilfing $\mathrm{M}$ : Determination of mexiletine in biological fluids by High - Performance Liquid Chromatography. J Chromatogr 1982; 230: 97-105.

12. Lanchote VL, Bonato PS, Dreossl SAC, Gonqalves PVB, Cesarino EJ and Bertucci C: High-Performance Liquid Chromatographic determination of mexiletine enantiomers in plasma using direct and indirect enantioselective separations. J. Chromatogr B 1996; 685: 281-289.

13. Abolfathi Z, Belanger PM, Gilbert M, Rouleau JR and Turgeon J: Improved High - Performance Liquid Chromatographic assay for the stereoselective deter-mination of mexiletine in plasma. J Chromatogr 1992; 579: 366-370.

14. Tatar Ulu S: Development of an HPLC method for the determination of mexiletine in human plasma and urine by solid-phase extraction. Talanta 2007; 72: 1172-1177.

15. Li S, Liu G, Jia J, Liu Y, Pan C, Yu C, Cai Y and Ren J: Simultaneous determination of ten antiarrhythmic drugs and a metabolite in human plasma by Liquid Chromatography-Tandem Mass Spectrometry. Journal Chromatogr B 2007; 847: 174-181.

16. Minnigh MB, Alvin JD and Zemaitis M: Determination of plasma mexiletine levels with Gas Chromatography-Mass Spectrometry and selected-ion monitoring. J Chromatogr B 1994; 662: 118-122.

17. Kempton J, Manoukian A, Levine B and Smialek J: A mexiletine intoxication. J Anal Toxicol 1994; 18: 346-347.

18. Rohrig $\mathrm{T}$ and Harty L: Postmortem distribution of mexiletine in a fatal overdose. J Anal Toxicol 1994; 18: 354-356.

19. USP 26/NF23: The United States Pharmacopeia, 26th Rev, and the National Formulary, United States Pharmacopeial Convention, Rockville, Edition 21 ${ }^{\text {st }}$, 2003: 2439.

20. British Pharmacopeia: Her Majesty's Stationery Office, London, Vol. II, 1993, 1012-1013.

21. El-Hefnawey GB, El-Hallag IS, Ghoneim EM and Ghoneim MM: Voltammetric behavior and quantification of the sedative-hypnotic drug chlordiazepoxide in bulk form, pharmaceutical formulation and human serum at a mercury electrode. J Pharm Biomed Anal 2004; 34: 75-86.

22. Corti P, Corbini G, Gratteri P, Furlanetto S and Pinzauti S: Determination of some quinolones in tablets, human plasma and urine by differential-pulse polarography. Int $\mathrm{J}$ Pharm 1994; 111: 83-87.

23. Radi A and Elmogy T: Differential pulse voltammetric determination of carvedilol in tablets dosage form using glassy carbon electrode. Farmaco 2005; 60: 43-46.

24. Dogan B and Ozkan SA: Electrochemical behavior of carvedilol and its adsorptive stripping determination in dosage forms and biological fluids. Electroanalysis 2005; 17: 2074-2083. 
25. Laviron E, Roullier L and Degrand C: A multilayer model for the study of space distributed redox modified electrodes: Part II. Theory and application of linear potential sweep voltammetry for a simple reaction. J Electroanal Chem 1980; 112: 11-23.

26. Yilmaz B and Ekinci D: Voltammetric behavior of carvedilol in non-aqueous media and its analytical determination in pharmaceutical preparations. Rev Anal Chem 2011; 30: 187-193.
27. Guidance for Industry Bioanalytical Method Validation: US Department of Health and Human Services, Food and Drug Administration, Center for Drug Evaluation and Research, Rockville, MD, 2001.

28. The European Agency for the Evaluation of Medicinal Products. ICH Topic Q2B Note for Guideline on Validation of Analytical Procedures: Methodology GPMP/ICH/281/95, 1996.

How to cite this article:

Yilmaz B and Nazik G: Determination of mexiletine in pharmaceutical preparations by linear sweep voltammetry. Int J Pharmacognosy 2015; 2(7): 335-41. doi link: http://dx.doi.org/10.13040/IJPSR.0975-8232.IJP.2(7).335-41.

This Journal licensed under a Creative Commons Attribution-Non-commercial-Share Alike 3.0 Unported License

This article can be downloaded to ANDROID OS based mobile. Scan QR Code using Code/Bar Scanner from your mobile. (Scanners are available on Google Playstore) 